\title{
EL DIÁLOGO EN EL PENSAMIENTO DE HANS-GEORG GADAMER (1900-2002)
}

Fernando Caloca*

El pensamiento de Gadamer se inscribe dentro de la tradición alemana que hizo la transición del neokantismo a la fenomenología y a la hermenéutica. En particular, su hermenéutica filosófica es deudora del giro lingüístico que tomó la filosofía a partir de Heidegger.

La aproximación de Gadamer a la ontología se debe a la influencia que sobre él ejerció la idea de que el lenguaje es la constitución fundamental del Dasein. En los seminarios del joven Heidegger se hacía revivir ese llamado 'acontecer lingüístico' que es la filosofía de los griegos. Gadamer recuerda con admiración cómo Heidegger dialogaba con el pensamiento de Platón y de Aristóteles como si esos interlocutores estuvieran presentes y lo interpelaran. ${ }^{1}$ Las preguntas de los propios griegos se volvían a ver claras y contundentes.

Sabemos que de esta lectura de los griegos y del enorme y poderoso influjo de la fenomenología de Husserl, fue probable que Heidegger se haya convencido de la tesis del olvido del ser. Su crítica radical al lenguaje de la metafísica lo hizo escribir Ser y Tiempo (1927) en un lenguaje difícil, críptico, e incluso, más tarde, abandonando el concepto

* Departamento Académico de Estudios Generales, ITAM.

${ }^{1}$ Verdad y método II, 1992, Salamanca, Sígueme, p. 380, trad. Manuel Olasagasti (en adelante VMII). Ver también Los caminos de Heidegger, 2002, Barcelona, Herder, trad. Ángela Ackermann Pilári. 
FERNANDO CALOCA

de la hermenéutica, lo llevó a la penuria lingüística hasta el punto de que muchos estudiosos de su obra consideran hoy que en ese nuevo lenguaje del Heidegger tardío hubo más poesía que pensamiento filosófico.

Así, uno de los temas que yo he abordado -dice Gadamer- ha sido la búsqueda de vías para expresar el lenguaje de Heidegger sobre el ser, un ser que no es el ser del ente. Esto me aproximó más a la historia de la hermenéutica clásica y me obligó a destacar lo nuevo en la crítica de la misma. Mi idea es que ningún lenguaje conceptual, ni siquiera lo que Heidegger llama 'lenguaje de la metafísica', significa un hechizo irremediable para el pensamiento con tal que el pensador se confíe al lenguaje, esto es, entre en diálogo con otros pensantes y con los que piensan de otro modo. Por eso, admitiendo la crítica al concepto de subjetividad hecha por Heidegger, concepto en el que demostró la supervivencia de la idea de sustancia, intenté detectar en el diálogo el fenómeno originario del lenguaje. Esto significaba a la vez una reorientación hermenéutica de la dialéctica, desarrollada por el idealismo alemán como método especulativo, hacia el arte del diálogo vivo en el que se había realizado el movimiento intelectual socrático-platónico. ${ }^{2}$

Admitiendo la crítica de Heidegger a la subjetividad y convirtiéndola en una clave de su propia hermenéutica filosófica, Gadamer optó por investigar ese fenómeno originario del 'acontecer lingüístico'. El retorno a los griegos y, en particular, los diálogos de Platón fueron a partir de sus primeros años de formación académica sus permanentes y más asiduos ejercicios hermenéuticos.

La hermenéutica de Gadamer afirma que el lenguaje pertenece al diálogo, es decir, el lenguaje no es proposición y juicio, sino únicamente es si es pregunta y respuesta-respuesta y pregunta. Por supuesto que el carácter permanente de la preocupación por el lenguaje no se le revelaba a Gadamer solamente en la manera en como Heidegger se acercaba a los

${ }^{2}$ VMII, p. 321. 
problemas y en los diálogos de Platón, sino que también fue la poesía de Hölderlin, Rilke y el círculo de Stefan Georg en el que tuvo la posibilidad de descubrir que la experiencia del arte es el verdadero órgano de la filosofía. Asimismo, la dialéctica de Hegel fue objeto de interesantes investigaciones ${ }^{3}$ que luego se verían reflejadas en su obra más importante: Verdad y método. ${ }^{4}$ El pensamiento de Gadamer es deudor de por lo menos tres autores clásicos de la filosofía: Platón, Hegel y Heidegger.

En este artículo sobre el diálogo en el pensamiento de Hans-Georg Gadamer se tratarán los siguientes aspectos: primero, se comentará la influencia del modelo platónico del diálogo en la hermenéutica de Gadamer. Se analizará el modelo del arte como ejemplo de la estructura dialógica de la experiencia hermenéutica y finalmente acercaremos esta idea de Gadamer al campo de la educación, específicamente a la labor que los maestros y los alumnos de Estudios Generales realizan en el ITAM. Desde luego que no se trata de agotar el tema ${ }^{5}$ sino tan sólo de ofrecer algunas observaciones en torno a la idea de diálogo en este autor.

\section{El modelo platónico del diálogo}

Gadamer es un filósofo que mantiene contacto filológico y filosófico con la obra de los filósofos griegos. ${ }^{6}$ De acuerdo con su hermenéutica

${ }^{3}$ La dialéctica de la conciencia en Hegel (1973), Valencia, Cuadernos Teorema, 1980. La dialéctica de Hegel: cinco ensayos hermenéuticos (1971), 1980, Madrid, Cátedra.

${ }^{4}$ Verdad y método I, 1977, Salamanca, Sígueme, trad. Ana Agud Aparicio y Rafael de Agapito (en adelante VMI) .

${ }^{5}$ Prácticamente toda la obra de Gadamer ofrece diferentes aproximaciones a este tema fundamental de su filosofía hermenéutica.

${ }^{6}$ Los volúmenes V, VI, y VII de sus Gesammelte Werke Mohr, Tubinga, 198595, 10 vols. están dedicados enteramente a la filosofía griega (GW). En español se ha publicado El inicio de la filosofía occidental (1988), 1995, Barcelona, Paidós, trad. R. A. Diez y C. Blanco, y El inicio de la sabiduría (1999), 2001, 
FERNANDO CALOCA

filosófica, no se puede cultivar la filosofía sin este diálogo que se prolonga hasta nuestros días. La relevancia del análisis que Gadamer hace del tema del diálogo no proviene de Heidegger sino de sus estudios directos sobre Platón. Gadamer, siguiendo a Platón, concibe el discurso filosófico como diálogo. Gadamer sostiene que el diálogo es la estructura originaria del pensar. La dialéctica de pregunta y respuesta se cumple en el propio pensamiento. El pensamiento es el 'diálogo del alma consigo misma' ${ }^{7}$ La forma como Platón concibe el diálogo le permite a Gadamer dejarle a la hermenéutica la más amplia generalidad. La hermenéutica como teoría de la comprensión no considera cada enunciado que interpreta en su valor lógico, sino que dialoga con la pretensión de que lo que ahí se dice o se toma como enunciado es una respuesta a una pregunta. Y este trabajo hermenéutico de saber la pregunta se da también cuando conversamos. Nadie analiza primero y después se comunica. Sino que conforme la comunicación se da y en la medida en que la comunicación fluye nos percatamos del constante ir y venir en el que de pronto ya tenemos y construimos lo que es común: preguntas y respuestas en torno a un tema.

Lo que caracteriza a la conversación frente a la forma endurecida de las proposiciones que buscan su fijación escrita es precisamente que el lenguaje realiza aquí en preguntas y respuestas, en el dar y tomar, en el argumentar en paralelo y en el ponerse de acuerdo, aquella comunicación de sentido cuya elaboración como arte es la tarea de la hermenéutica frente a la tradición literaria. Por eso cuando la tarea hermenéutica se concibe como entrar en diálogo con el texto, esto es algo más que una metáfora, es un verdadero remedo de lo originario. ${ }^{8}$

Barcelona, Paidós, trad. Antonio Gómez Ramos, así como textos en diferentes antologías, vgr: "La filosofía griega y el pensamiento moderno" (1978) y "Platón como retratista” (1988) en Antología, Jean Grondin, 2001, Salamanca, Sígueme, trad. Constantino Ruiz Garrido y Manuel Olasagasti (en adelante AN). ${ }^{7}$ AN, p. 77.

${ }^{8}$ VMI, p. 446 (subrayado mío). 
Desde sus primeros años de formación académica Gadamer se percató, en su condición de filólogo, que los diálogos de Platón son quizá el ejemplo más acabado de la paideia griega. La obra de Platón es un corpus completo en el que se conserva la huella de cómo se construye todo el pensamiento de un filósofo. La totalidad desde la que se lee y relee a Platón, es ya un punto de partida para su permanente praxis hermenéutica porque le hace ver la "armonía dórica de acción y discurso, de ergon y logos, de obra y lenguaje que los diálogos por si mismos presentan”. 9

Releer a Platón, desde el punto de vista filosófico, “consiste en reconducir con precisión los enunciados conceptuales que aparecen en el diálogo a la realidad dialogal de la que derivan”. ${ }^{10}$ La idea del diálogo proviene pues de Platón y el arte del diálogo también: la dialéctica.

Dialéctica es el arte de llevar una conversación, y esto incluye el arte de llevar esta conversación consigo mismo y de perseguir el entendimiento consigo mismo. Es el arte de pensar. Pero esto equivale al arte de indagar el significado de lo que se piensa y se dice. De ese modo se sigue un camino o, más exactamente, se está en un camino. Porque existe algo que cabe llamar "predisposición natural del hombre a la filosofía". Nuestro pensamiento no se detiene en lo que alguien significa con esto o aquello sino que el pensar se trasciende a sí mismo. La obra de los diálogos platónicos lo expresa a su modo: remite a lo uno, al ser, al 'bien’ que se expresa en el orden del alma, de la constitución de la ciudad y de la estructura cósmica. ${ }^{11}$

Gadamer considera los diálogos platónicos como discursos-guía en los que Platón nos hace ver el saber del no saber. En los diálogos socráticos, Platón se deja guiar a su vez por un espíritu que lo conven-

${ }^{9}$ VMII, p. 396. La praxis hermenéutica consiste en ir al sentido original de los diálogos (por el lado filológico) e ir al sentido original de la dialéctica (por el lado filosófico).

${ }^{10}$ Ibid.

${ }^{11}$ VMII, p. 396-7. 
FERNANDO CALOCA

ce de su nueva misión. El espíritu que anima esta voluntad conceptual del origen de Platón, es la figura de Sócrates. Platón nos explica quién y qué era Sócrates a través de los diálogos. El modelo socrático le hace valorar la docta ignorantia del ciudadano ateniense.

Sócrates representa, para Gadamer, una clara oposición a la revolución sofista de Atenas. El sofista es aquel sujeto que lo que quiere es siempre tener razón; aprende el arte de persuadir más que el arte de pensar; adorna sus argumentos o distrae a sus interlocutores para lograr seguir siendo reconocido. Quizá el rasgo de un sofista que más claramente lo hace ver como lo opuesto a la mayéutica socrática es que el sofista no escucha.

Si no escuchamos con aquella benevolencia que sabe reconocer al otro en lo que él piensa, entonces somos sofistas. ${ }^{12}$

Gadamer, siguiendo a Heidegger, reconoce en la figura de Sócrates la crítica más contundente a la soberbia de la ciencia y la técnica actuales. El lego, el idiotes asume un papel completamente nuevo entre el erudito y el sabio. ${ }^{13}$ La sabiduría del filósofo ateniense es de una naturaleza tal que:

trata de convencer al otro, al interlocutor de Sócrates, de que no sabe nada, y esto significa que su saber sobre sí mismo y sobre su vida se torna en meras presunciones. O, para decirlo con la frase audaz de Platón en la Carta Séptima: no se refuta sólo su tesis, sino su alma. [...] No se trata evidentemente de un saber técnico, sino de otro género de saber mas allá de todas las pretensiones y competencias especiales de una superioridad en el saber, mas allá de todas las tejnai y epistemai conocidas. Este otro saber significa el 'giro hacia la idea' que está detrás de todas las soflamas de los presuntos sabios. ${ }^{14}$

12 AN, p. 370.

13 Cfr. VMI, p. 50.

14 VMII, p. 396. 
El arte de conversar en Platón lo hace a uno situarse más allá del conocimiento positivo o instrumental. La constante en la obra de Gadamer es la crítica a la dominación del conocimiento científico y a su metodología tradicional. Platón, a través de Sócrates, nos hace comenzar un tipo diferente de conocimiento: el conocimiento reflexivo.

La primacía hermenéutica que Gadamer dará a la pregunta en el conocimiento reflexivo nace de esta observación acerca de la docta ignorantia, que consiste en saber que no se sabe. ${ }^{15}$ La docta ignorantia se asume en la hermenéutica como estructura esencial de la experiencia humana del mundo:

la estrecha relación que aparece entre preguntar y comprender es la que da a la experiencia hermenéutica su verdadera dimensión. El que quiere comprender puede desde luego dejar en suspenso la verdad de su referencia; puede desde luego haber retrocedido desde la referencia inmediata de la cosa a la referencia de sentido como tal, y considerar ésta no como verdad sino simplemente como algo con sentido, de manera que la posibilidad de verdad quede en suspenso: este poner en suspenso es la verdadera esencia original del preguntar. ${ }^{16}$

La dimensión a la que aquí se hace referencia es la dimensión del comprender humano. Para comprender algo que no es todavía verdad, el sujeto formula sus preguntas pero puede ‘dejar en suspenso' lo que él crea que hay; puede asimismo 'dejar en suspenso' lo que el texto o la cosa misma le dice para tratar de comprender desde el sentido de lo que ahí habla, en todo caso comprender es la posibilidad humana de acceder a la verdad. Cuando se comprende se comprende la verdad si no, no se comprende. Y se debe dejar que el texto o la cosa le diga algo a uno.

${ }^{15}$ Cfr. VMI, p. 439; VMII, p. 51-61.

${ }^{16}$ VMI, p. 453. 
FERNANDO CALOCA

No es el juicio, sino la pregunta la que tiene prioridad en la lógica, como confirman históricamente el diálogo platónico y el origen dialéctico de la lógica griega. ${ }^{17}$

En el diálogo concebido así es necesaria la apertura. Preguntar y responder es la lógica de ese acontecer lingüístico y de esa apertura que hace dinámico el conocimiento reflexivo. Pero al mismo tiempo la apertura es lo que orienta el diálogo hacia ese conocimiento como comunicación de sentido, mas allá del intercambio de palabras. El lenguaje en el diálogo es el medio en el que se abre la persona a la comunicación de sentido, abierta a su vez siempre a nuevas interrogaciones.

La hermenéutica para Gadamer, por tanto, no es algo que tenga que ver con reglas de interpretación. Comprender e interpretar no sólo es una actividad en torno a los textos sino que pertenece, siguiendo aquí a Heidegger, a la experiencia humana del mundo porque en ella siempre hay lenguaje de por medio. La hermenéutica filosófica investiga la esencia de ese comprender e interpretar humanos y para tal efecto, integra formas de experiencia que generalmente quedan fuera del campo científico pero que son las que nos pueden indicar con mayor precisión lo que significa la verdad como acontecimiento y apertura.

El modelo de la dialéctica platónica recupera esa apertura que supone la pregunta. El modelo del juego en el arte recupera esa comunicación de sentido que todo diálogo supone y que es tan importante para captar la estructura esencial de la experiencia humana del mundo.

Si la filosofía de Gadamer busca formas de experiencia en las que se exprese una verdad que no pueda ser verificada con la metodología científica tradicional; no sólo el arte, sino también la historia son las formas primeras y primarias de experiencia con las que se hace una crítica a la subjetividad que inició Heidegger, pero sobre todo se muestra ese fenómeno originario que es el lenguaje.

El análisis fenomenológico en la hermenéutica de Gadamer en particular le permitirá obtener los rendimientos metodológicos necesarios

${ }^{17}$ VMII, p. 58. 
para proceder a la expansión de la cuestión de la verdad en las ciencias del espíritu y mostrar el hilo conductor del giro ontológico de la hermenéutica. ${ }^{18}$ Uno de estos rendimientos es mostrar la identificación entre interpretación y comprensión. El fundamento de la interpretación es la comprensión y toda comprensión esta orientada o dirigida hacia una interpretación que en la medida que se logre llevar a cabo, será la medida en que habremos de acceder a la interpretación verdadera de una cosa o un texto, mediante la fusión de horizontes. La interpretación no es un acto secundario y posterior al de la comprensión, sino que comprender es siempre interpretar, y en consecuencia la interpretación es la forma explícita de la comprensión misma. Otro rendimiento metodológico importante sería el de mostrar cómo en todo comprender se da una experiencia de la verdad. Es decir, toda comprensión tiene como punto de partida la experiencia de la verdad:

en la experiencia [...], que no deja inalterado al que la hace, [...] preguntamos por el modo de ser de lo que es experimentado de esta manera. ${ }^{19}$

El hecho de que la interpretación de un texto no tenga como objetivo sólo comprender al autor sino también la verdad del texto, le permite a Gadamer superar esa hermenéutica clásica que se asume como hermenéutica normativa más que como hermenéutica filosófica. Siempre interpretamos desde un momento histórico determinado y por supuesto que lo que interpretamos o tratamos de comprender también tiene su historia. Sólo cuando logramos fusionar los horizontes, tanto del texto como del intérprete, es que se produce la llamada comprensión de la verdad del texto. Pero si siempre interpretamos desde nuestra historia cabe aceptar también que siempre haremos interpretaciones diferentes. Así, todas estas observaciones de la hermenéutica nacen de formas de experiencia humana del mundo cuando estamos ante el reto de comprendernos.

${ }^{18}$ VMI, p. 225 s. y p. 461 s.

${ }^{19}$ Ibid., p. 142. 
FERNANDO CALOCA

\section{El modelo del juego}

El análisis fenomenológico del modo de ser de la obra del arte comienza por la equivalencia entre la experiencia de la verdad del arte y la experiencia de juego. Para determinar el concepto de juego, Gadamer comienza por distinguir entre el juego y el comportamiento del jugador. El jugador juega, sin embargo "el juego sólo cumple el objetivo que le es propio cuando el jugador se abandona del todo al juego." ${ }^{20}$ Esto quiere decir que el comportamiento subjetivo del jugador no es lo mismo que el juego. El juego es un fenómeno cuya esencia no se agota en la subjetividad del que juega. La esencia del juego es algo más.

Nuestra tesis es, pues, que el ser del arte no puede determinarse como objeto de una conciencia estética, porque a la inversa el comportamiento estético es más que lo que él sabe de sí mismo. Es parte del proceso óntico de la representación, y pertenece esencialmente al juego como tal. ${ }^{21}$

30 La esencia del juego es su representación y no es el sujeto el que contiene ese modo de ser del juego. El jugador juega, y sabe que juega, pero no puede al mismo tiempo tener conciencia del juego como tal porque perdería su cualidad de jugador. "El jugador -dice Gadamersabe muy bien lo que es el juego, y que lo que hace 'no es más que juego'; lo que no sabe es que lo 'sabe'”. ${ }^{22}$ Esta es la docta ignorantia del hombre en el juego. En la experiencia de jugar no se sabe qué es jugar, sino que simplemente se juega. En el jugador no podemos hallar la esencia del juego. Hay que descubrir el modo de ser del juego tal cual: el juego en sí mismo. Se reconoce que "el sujeto [entonces] del

${ }^{20}$ Ibid., p. 144.

${ }^{21}$ Ibid., p. 161.

${ }^{22}$ Ibid., p. 144. 
juego no son los jugadores, sino que a través de ellos el juego simplemente accede a su manifestación”. 23

Gadamer sostiene que hay un "primado del juego frente a la conciencia del jugador”. ${ }^{24}$ El juego, podría decirse se encuentra a medio camino entre la conciencia del jugador y la realidad que se forma o a la que se refiere todo juego. Esta estructura “del sentido medio del juego”, es decir, este movimiento de vaivén sin intención, objetivo o esfuerzo, es lo que atrapa al jugador para que se arriesgue a la empresa. Esta estructura es la que permite al jugador liberarlo de toda iniciativa, "que es lo que constituye el verdadero esfuerzo de la existencia”. ${ }^{25}$ El argumento de fondo, en favor de la fascinación que ejerce el juego, está en el concepto aristotélico de la vida.

Lo que está vivo -dice Gadamer-lleva en sí mismo el impulso de movimiento, es auto movimiento. El juego aparece entonces como el auto movimiento que no tiende a un final o una meta, sino al movimiento en cuanto movimiento, que indica, por así

${ }^{23}$ Ibid., p. 145. "Cuando una palabra -dice Gadamer- se transfiere a un ámbito de aplicación al que no pertenece en origen, cobra relieve su auténtico significado original”: idem. Gadamer recurre al significado de los usos metafóricos de la palabra juego. En expresiones como 'juegos de luces', ‘juego de las olas', 'juego de la parte mecánica en una bolera', 'juego articulado de los miembros', ‘juego de fuerzas', 'juego de las moscas', ‘juegos de palabras' etc. el significado metafórico alude a 'un movimiento de vaivén que se repite continuamente'. La actualidad de lo bello. El arte como juego, símbolo y fiesta, 1991, Barcelona, Paidós/ICE-UAB, p. 66, trad. Antonio Gómez Ramos (en adelante $A B$ ). En este movimiento repetitivo no hay sujeto que realice acción alguna. El término Spiel como danza también hace referencia a un movimiento que no tiene objeto o fin. En este sentido lingüístico, el juego no es actividad del jugador, sino que el juego es "pura realización de movimiento”, VMI, p. 146. Este movimiento de vaivén es tan importante para Gadamer que le resulta indiferente quién es el que realiza dicho movimiento.

${ }^{24}$ Ibid., p. 147.

${ }^{25}$ Ibid., p. 148. 
FERNANDO CALOCA

decirlo, un fenómeno de exceso, de la autorepresentación del ser viviente. ${ }^{26}$

En otras palabras significa que el juego es lo que más se parece a la vida. Si el modo de ser del juego es la forma del movimiento de la naturaleza, el hombre juega porque la naturaleza juega, y no a la inversa.

El análisis fenomenológico de Gadamer nos muestra que el juego "es un puro auto manifestarse, precisamente porque es naturaleza y en cuanto que es naturaleza”. ${ }^{27}$ Por tanto, el rasgo general de todo comportamiento lúdico es este "exceso que pugna por alcanzar su representación en el mundo de los seres vivos”. ${ }^{28}$ La esencia del juego tiene un principio fundamental que sostiene y confirma la tesis de que "el verdadero sujeto del juego no es el jugador sino el juego mismo.”29 “Todo jugar es un ser jugado." 30

La observación fenomenológica de Gadamer se dirige a saber qué es la experiencia del arte. Saber cuál es su verdad aunque ella no sepa lo que es y aunque no pueda decir lo que sabe, es recuperar esa docta ignorantia a la que ya hacíamos referencia.

Gadamer caracteriza el juego humano como fenómeno intencional.

32 La característica que el hombre añade a todo jugar es su intencionalidad. El juego humano tiene reglas e instrucciones que forman el espacio lúdico propiamente. El juego como actividad intencional muestra algo

${ }^{26} A B$, p. 67.

${ }^{27}$ VMI, idem.

${ }^{28}$ AB, p. 67.

${ }^{29}$ VMI, p. $149-50$.

${ }^{30}$ Ibid., p. 149. Recordemos que para la fenomenología la singularidad de los actos se definen desde el sentido de lo que contienen; es decir, desde lo jugado y lo auto movido, en este caso. Eso es lo que aparece originariamente, con anterioridad a cualquier construcción teórica; en otras palabras, ése es el fenómeno. A él se refiere el hecho de jugar; el sentido del juego está en la presencia de algo distinto de él mismo; es decir, que es intencional. 
como si algo. ${ }^{31}$ Cuando el hombre juega, juega a algo. Ese algo, que es a lo que un hombre juega es en principio a un juego: lo que hace el hombre cuando juega es también ordenarse y disciplinarse a sus propios movimientos, como si tuvieran fines. Pero el sometimiento es elegido por el que juega. Y una vez elegido el juego, incluso elige dentro del espacio lúdico al que se somete. Por eso: "El juego humano requiere su propio espacio de juego." ${ }^{32}$ El espacio del juego humano es limitado y ordenado no por el jugador sino por el juego mismo. El hombre que no respete las reglas del juego, no juega. Esencialmente lo que hace el hombre cuando juega es realizar la autorepresentación del propio juego. Ahí donde el juego pide al jugador el cumplimiento de ciertas tareas, el jugador se libera de su ser jugado y se asimila al juego mismo. Sólo en la medida que el jugador se entregue, el juego se representa. Pero desde la perspectiva del juego mismo, el juego se auto representa. "El juego humano, dice Gadamer, sólo puede hallar su tarea en la representación, porque jugar es siempre ya un representar." ${ }^{33}$ La idea de representación tiene, en este sentido, un componente intencional propio del fenómeno. “Toda representación es por su posibilidad representación para alguien. "34 En relación con el concepto de juego que Gadamer nos describe, aunque el juego mismo sea auto representación, el juego humano no se agota en sí mismo, sino que va mas allá de sí, y quien

${ }^{31}$ Cfr. "El juego del arte” (1975), en Estética y hermenéutica, 1996, Madrid, Tecnos, p. 131, intr. Ángel Gabilondo, trad. Antonio Gómez Ramos (en adelante $E H$ ).

${ }^{32}$ VMI, p. 150.

${ }^{33}$ Ibid., p. 151. El traductor de Verdad y método nos aclara que el término alemán das Spiel, en inglés play, posee una asociación al mundo del teatro, "ya que una pieza teatral también es un Spiel, juego; los actores son Spieler, jugadores; la obra no se 'interpreta' sino que se 'juega': es wird gespielt”, ibid., p. 143.

${ }^{34}$ Ibid., p.152. 
FERNANDO CALOCA

capta la autorepresentación es alguien, ya sea el que tiene la conciencia de jugar o el espectador. ${ }^{35}$

Gadamer aplica sus reflexiones igualmente al juego y a la representación escénica. El juego y la representación escénica son “representación para...” Esto no quiere decir que los jugadores jueguen para representar. Mas bien, los jugadores participan de una representación que en el espectador se comprende como totalidad.

El jugador experimenta el juego como una realidad que le supera, y esto es tanto más cierto cuando realmente hay 'referencia' a una realidad de este género, como ocurre cuando el juego parece como representación para un espectador. ${ }^{36}$

El espectador en principio es el propio jugador y, "si algo se representa aquí, aunque sólo sea el movimiento mismo del juego, también

${ }^{35}$ Mientras que en el juego hay un primado del mismo sobre la conciencia del jugador; en el arte, existe un primado de la experiencia sobre la abstracción del intérprete. Mientras el juego cumple plenamente con su función en la medida en que el jugador se deja llevar por el juego; la obra de arte conquista su verdadero ser en el hecho de que se convierte en experiencia que transforma a la persona que deja ser el arte en él. Si el juego tiende a absorber a los jugadores, a dominarlos, a convertirlos en sujetos del juego mismo; el arte deja en la persona el ser mismo, es decir, que el sujeto de la experiencia del arte no es la subjetividad de la persona sino la obra misma.

${ }^{36}$ VMI, p.153. Resulta ilustrativa la siguiente explicación: "La palabra representación puede significar dos cosas. Primero, la Venus de Milo está presente en el Louvre de París y está representada (en sus copias o reproducciones) en los museos de Barcelona, Madrid... Segundo, Hamlet no está presente en ninguna parte y se representa en los teatros de Barcelona, Madrid... (...) El significado hermenéutico de la palabra representación es el segundo. (...) el ser de Hamlet es representación. Su ser no se separa de su representación. La representación de Hamlet (la interpretación de la Novena sinfonía...) es una representación que no representa (no depende de una presencia anterior)”: J. Pegueroles, “Presencia y representación”, en Espíritu, 1993, vol. 42, n' 107, p. 7. 
puede decirse del espectador que 'se refiere' al juego, igual que yo, al jugar aparezco ante mi mismo como espectador.(...) El juego es, en definitiva, auto representación del movimiento de juego.”37 Sin embargo, el espectador también es aquel ante quien la representación alcanza su idealidad más plena, es decir el espectador que ve el juego de los jugadores es un co-jugador. La representación dramática es un juego, en el mismo sentido que en inglés su utiliza la palabra play. La representación dramática es un mundo cerrado en sí mismo, pero abierto hacia el lado del espectador. La representación dramática tiene esta estructura de mundo cerrado porque el espacio lúdico tiene un orden y un límite impuesto por su propio movimiento. Pero está abierto hacia el lado del espectador porque es él quien realiza completamente lo que es el juego (representación) como tal. Es decir, aunque sea un mundo cerrado, el espectador es quien le da pleno significado a la representación. El espectador, como ya dijimos, es, por eso, para quien el juego se representa en su totalidad. Los actores-jugadores en un drama participan representando su papel para que toda la obra sea representada al público. La idealidad del drama se da en el espectador-co-jugador porque "lo que ocurre al juego como tal, cuando se convierte en juego escénico es un giro completo. El espectador ocupa el lugar del jugador." ${ }^{38}$ Es decir, que en una representación dramática el espectador es quien comprende o abarca todo lo que el juego le requiere. Para Gadamer, el espectador tiene una posición privilegiada metodológicamente, en el sentido de ser él, quien comprende el juego y puede aislarse de la conducta de los jugadores. Los actores no se pueden agotar en el juego, porque tienen que representar su papel particular. Esto, por supuesto, no significa que el actor no juegue o no pueda percibir el conjunto de su representación en la que él representa sólo un papel. Pero es el espectador el que puede percibir una totalidad de sentido más plena en cuanto que el juego posee para él

\footnotetext{
${ }^{37} A B$, p. 68.

${ }^{38}$ VMI, p. 153.
} 
FERNANDO CALOCA

un contenido de sentido que tiene que ser comprendido y que por lo tanto puede aislarse de la conducta de los jugadores. Aquí queda superada en el fondo la distinción entre jugador y espectador. El requisito de referirse al juego mismo en su contenido de sentido es para ambos el mismo. ${ }^{39}$

Si ya señalamos que el juego es movimiento, y mejor aún auto movimiento, es claro que hay una estructura. Esa estructura sin sustrato aparente, tiene también la característica de ser representación y mejor aún auto representación. Si ya aclaramos que es en el espectador donde podemos ver manifestada la presencia de la representación, y si ya vimos que la representación dramática es el juego humano donde se alcanza esta perfección, agreguemos que Gadamer llama a todo este modo de ser del juego como tal "transformación en una construcción”. La diferencia entre el juego en el sentido común del término y juego como la esencia de la obra de arte reside en el hecho de que en el arte se da una trasmutación de la forma. ${ }^{40}$ Además es en el arte donde Gadamer quiere mostrar la esencia de la experiencia de la verdad. ${ }^{41}$ En tanto que el juego, asociado a la representación dramática, es auto representación independientemente de lo que hacen los jugadores (actores), "le conviene el carácter de obra, de ergon, no sólo de energeia. Es en este sentido -dice Gadamer- como lo llamo ‘construcción'”, ${ }^{4}$

${ }^{39}$ VMI, p. 154.

${ }^{40}$ Cfr. G. Vattimo, Poesía y ontología, 1992, Barcelona, Gedisa, p.178.

41 "El hilo de Ariadna de la hermenéutica filosófica, según Gadamer, no es la hermenéutica clásica, con sus pretensiones metódicas desde la subjetividad (Schleiermacher y Dilthey), sino la experiencia del arte en su realidad óntica como acontecimiento de mediación (Hegel-Heidegger)”: Juan Manuel Almarza Meñica, "La experiencia hermenéutica del arte según Hans Georg Gadamer”, en Estudios Filosóficos 129, 1996, p. 375.

${ }^{42}$ La nota del traductor de Verdad y método I aclara respecto a la palabra 'construcción', lo siguiente: “Con el término ‘construcción' traducimos al alemán Gebilde, cuyo significado literal es 'una formación ya hecha o consolidada', y que está en relación etimológica con el verbo bilden, 'formar', y con el sustantivo Bild, 'imagen, figura'. Nos impide traducirlo por 'forma- 
Pegueroles conceptualiza claramente otra aportación del análisis gadameriano de la distinción e indistinción en el juego:

El concepto de juego (Spiel) es una de las ideas centrales de Verdad y método. El juego sólo es cuando se juega y no representa nada. La hermenéutica de Gadamer pone entre el ser y su representación, a la vez, distinción e indistinción. Hamlet sólo es cuando es representado: indistinción. Pero Hamlet de algún modo es antes de su representación: distinción. ${ }^{43}$

Recapitulando entonces, el juego es, para Gadamer, "un movimiento de vaivén que se repite continuamente". ${ }^{44}$ En este sentido, el arte es un fenómeno intencional que ofrece un auto movimiento que nos exige participación. El problema de la identidad hermenéutica de la obra de arte está dado por este ‘jugar-con’ en el que hay que ‘entender algo’.

Para saber si entendemos correctamente lo que una obra de arte nos comunica es necesario considerar el concepto de la no-distinción. En la comprensión de la obra de arte se da una determinación que necesariamente implica un espacio para ser rellenado por quien la reciba. Para Gadamer no hay distinción de principio entre la obra de arte y la percepción que se hace de ella. La percepción de una obra de arte requiere de nuestra comprensión ya que “es la no-distinción entre el modo particular en que una obra se interpreta y la identidad misma que hay detrás de la obra lo que constituye la experiencia artística”. ${ }^{4}$ Sin embargo, sabemos que una obra de arte no se agota nunca, porque

ción’ el carácter de nomen actionis de este término, así como el haberlo utilizado ya para traducir Bildung, que es también el nomen actionis de la misma raíz. En este contexto ‘construcción' debe entenderse pues en parte como ‘constructo', y en parte como ‘configuración', en cualquier caso como el producto acabado de este género de actividades formadoras y conformadoras": VMI, p. 154.

43 J. Pegueroles, op. cit., p. 6.

${ }^{44} A B$, p. 66.

${ }^{45} A B$, p. 79. 
FERNANDO CALOCA

ninguna obra de arte nos habla siempre del mismo modo. La consecuencia es que nuestra respuesta debe ser cada vez distinta. "Esto queda claro - dice Gadamer- si se ha de respetar la 'verdad' del 'arte' en la infinita variedad de sus expresiones.” 46 Lo propio de una conciencia estética como la que había en el siglo XIX, distinguía claramente entre lo que es una obra de arte y lo que experimentamos cuando nos acercamos al arte. La distinción estética es "la abstracción que sólo elige por referencia a la calidad estética (de una obra) como tal”. ${ }^{47}$ Sabemos que este planteamiento va contra la subjetivización de la estética por la crítica kantiana. $^{48}$

La identidad de la obra no está garantizada por una determinación clásica o formalista cualquiera, sino que se hace efectiva por el modo en que nos hacemos cargo de la construcción de la obra misma como tarea. ${ }^{49}$

Esto hace significativa la palabra wahrnehmen (tomar nehmen algo como verdadero wahr) que significa percibir. Por tanto, está en el percibir, la respuesta a la cuestión de cómo es que una obra nos dice algo más, algo nuevo. Percibir no es captar con los sentidos solamente, sino mediar para alcanzar el verdadero ser.

Para entender lo que es percibir mas allá de lo puramente estético, Gadamer, introduce el término de la no-distinción estética. Precisamente si lo que se capta a través de la experiencia estética es aquello que rebasa toda consideración conceptual (Kant) entonces no hay distinción alguna cuando tomamos el modo de ser de la obra de arte como juego.

La no-distinción estética es la in-diferenciación “entre el modo particular en que una obra se interpreta y la identidad misma que hay detrás de la obra”, 50

${ }^{46}$ VMII, p. 15.

${ }^{47}$ VMI, p. 125.

${ }^{48}$ Ibid., p. 75 s.

${ }^{49} A B$, p. 77.

${ }^{50} A B$, p. 79. 
lo imitado en la imitación, lo configurado por el poeta, lo representado por el actor, lo reconocido por el espectador es hasta tal punto la intención misma, aquello en lo que estriba el significado de la representación, que la conformación poética o la representación como tal no llegan a destacarse. ${ }^{51}$

Esto ocurre en el modo como el arte se nos da: la obra de arte no es primero en sí y, después, en su representación. Para tener una experiencia estética probablemente tengamos que hacer abstracción de lo que nos interpela significativamente en una obra, pero de lo que se trata es de ver que toda distinción es secundaria si lo que queremos es captar la unidad, la totalidad de sentido, la mismidad de una obra. El ser de Hamlet es representación. El propio Gadamer confiesa su influencia kantiana a este respecto:

Lo que yo he descrito como la no-distinción estética constituye claramente el sentido propio del juego conjunto de entendimiento e imaginación, que Kant había descubierto en el 'juicio de gusto’. 52

En este sentido es claro también que Kant "estaba orientado primariamente hacia la belleza natural”. Por supuesto que con lo que no está de acuerdo es con la abstracción de una conciencia estética a partir de esta forma de concebir la percepción. Gadamer afirma que tanto en Kant como en nosotros lo que nos interpela de la naturaleza es "una especie de indeterminación” significativamente bella.

Incluso dentro de las artes interpretativas, como la representación dramática, hay que reconocer que las posibilidades de ser de la obra pueden ser muchas; sin embargo no podemos caer en el absurdo de aceptar versiones o interpretaciones que no estén determinadas por la obra misma. No es por tanto arbitraria la variación que puede haber de

${ }^{51}$ VMI, p. 162.

${ }^{52} A B$, p. 79. 
FERNANDO CALOCA

una interpretación a otra, o de una ejecución a otra, o de una representación a otra. Las variaciones se van dando por la obra misma o bien también por la tradición que esa misma obra ha creado. El criterio de la representación correcta es la identidad.

La medida de la corrección de las representaciones de Hamlet no es la semejanza, como cuando decimos: hoy representamos el mismo Hamlet que ayer, el Hamlet de hoy es repetición del de ayer. La medida o la corrección de la representación de Hamlet es la identidad: si en la representación se hace presente Hamlet mismo (y no una obra distinta). [...] Consecuentemente el criterio de la representación correcta solo puede ser la identidad. Que las representaciones A, B y C de Hamlet sean representaciones de Hamlet (identidad ideal de Hamlet). En una palabra, que Hamlet sea Hamlet, que Platón sea Platón, etc."53

Esta peculiaridad de las artes interpretativas permite ver con mayor claridad que toda obra de arte en sí misma es libertad de configuración, transformación en una construcción. Lo que nos acerca a la obra, o la identidad propiamente hermenéutica de la obra de arte, nos confirma que cada representación intenta ser una representación correcta porque la llamada "no distinción de la mediación respecto a la obra misma es la verdadera experiencia de ésta”. ${ }^{54}$ Mediación total significa para Gadamer que "la obra accede a su representación a través de ella y en ella”. 55

Crecer hacia dentro en el arte, significaría para Gadamer, crecer mas allá de nosotros mismos. La estructura dialógica de la referencia a la obra de arte adquiere connotaciones fundamentales al ser ésta la clave para reivindicar la praxis hermenéutica como tal.

53 J. Pegueroles, “El ser y la verdad”, en Espíritu, 1994, vol. 43 n 109, p. 16-7. Cfr. VMI, p. 164-5.

${ }^{54}$ Idem.

${ }^{55}$ VMI, p. 165. 
De la misma manera que se dice que el ser de la obra de arte es un juego que sólo se cumple en su recepción por el espectador, de los textos hay que decir que sólo en su comprensión se produce su vivificación. ${ }^{56}$

La hermenéutica sirve para desarrollar la posibilidad de transmitir al otro lo que uno piensa de verdad y obtener de él la respuesta. La obra de arte constituye un modelo para presentar cómo ocurre la comprensión a través del diálogo. Siguiendo a Almarza ${ }^{57}$ en su análisis de la praxis hermenéutica en Gadamer podríamos decir que las tres características del diálogo son:

1. Primado del diálogo frente a la conciencia del que dialoga. Gadamer lo llama el auto-olvido del lenguaje. Todo lo que estudia la lingüística queda inconsciente en las personas que hablan. En este sentido fenomenológico, la esencia del diálogo no puede ser comprendida a partir del comportamiento subjetivo de quienes realizan tal actividad. Los interlocutores dialogan, es decir hacen algo y no pueden al mismo tiempo estar pensando en que dialogan. Y en la medida en que eso que hacen es conversar, ninguno de los interlocutores sabe a dónde va o qué va a resultar de esto. El auténtico diálogo no resulta casi nunca como nosotros quisiéramos que fuese. Cuando uno de los interlocutores pretende conducir o dirigir la actividad del diálogo conforme a algún plan preestablecido destruye la posibilidad de que haya diálogo. Si acaso habrá un intento de intercambio pero no se da el diálogo como tal porque falta la dinámica propia que el diálogo mismo posee.

Llevar una conversación quiere decir ponerse bajo la dirección de un tema sobre el que se orientan los interlocutores. ${ }^{58}$

${ }^{56}$ L. E. Santiago Guervós, Hans-Georg Gadamer, 1997, Madrid, Ediciones del Orto, p. 34.

57 J. M. Almarza-Meñica, “La praxis de la hermenéutica filosófica según H. G. Gadamer”, en Estudios Filosóficos, 1985, Valladolid, Instituto Superior de Filosofía, vol. 34, p. 149-83.

${ }^{58}$ VMI, p. 445. 
FERNANDO CALOCA

2. El diálogo como ausencia del yo y como libertad. La forma efectiva del diálogo se puede describir partiendo del juego. Hay juego cuando se toma en serio el juego. Las personas que no son capaces de hacer esto se dice que no saben jugar. Esta idea de que el juego es algo libre, algo que nos permite ser diferentes o algo que nos lleva por donde quiere porque nos seduce es esencialmente similar a la esencia de una conversación. En un diálogo si sabemos dejarnos llevar ambos interlocutores por la ley de la cosa que rige esa conversación entramos en un contexto de movimiento que desarrolla su propia dinámica. La estructura de esa dinámica es la pregunta y la respuesta.

3. El diálogo como representación (en el sentido de hacer presente, no en el de poner una cosa en sustitución de otra) de la verdad de la cosa. La verdad que aparece en el diálogo es la verdad del logos. La lógica de toda conversación está en decir algo a alguien. Pero una vez dicho algo, alguien se siente interpelado y contesta. Muy probablemente su respuesta signifique para el otro una nueva pregunta. El diálogo implica un arte de ensayar. El arte de ensayar es el arte de preguntar. Preguntar "quiere decir poner al descubierto y poner en descubierto" ${ }^{59}$ Cuando el interlocutor hace una pregunta en algún diálogo de Platón pareciera que ya tiene al mismo tiempo la respuesta. Sócrates al introducir sus preguntas va ensayando con el interlocutor las respuestas que se van dando en el curso de su investigación. Sus preguntas poco a poco van reforzando la investigación de la verdad. En este sentido preguntar es pensar, es decir, un querer seguir preguntando hasta que aparezca la verdad del asunto.

Y no es ni lo que yo opino ni siquiera lo que yo sé o lo que el otro defiende o ha argumentado, sino lo que resulta de habernos sometido con libertad a lo que se nos presenta como la verdad de la cosa misma. De esta manera "la forma literaria del diálogo (platónico) devuelve lenguaje y concepto al movimiento originario de la conversación”. 60 Este aspecto Gadamer lo llama universalidad del lenguaje.

\footnotetext{
${ }^{59}$ Idem.

${ }^{60}$ Ibid., p. 446.
} 
EL DIÁLOGO EN GADAMER

\section{La praxis hermenéutica del diálogo en la educación}

Finalmente expresaremos algunas ideas acerca de lo que esta praxis hermenéutica implica en nuestra labor como maestros de Estudios Generales. La labor que los maestros hacen en las materias de Estudios Generales en el ITAM tiene mucha relación con la praxis hermenéutica de Gadamer.

Como ya hemos visto la labor del hermeneuta consiste, según Gadamer, en recuperar la estructura dialogal allí donde está oculta. En este sentido toda la labor que el maestro debe desarrollar en sus cursos es la de tratar de recuperar el proceso del pensar que no consiste en otra cosa que el ejercicio de preguntar y responder que se halla en los textos.

De cada clase en que se logra generar un verdadero diálogo surgen cosas nuevas, planteamientos originales o simplemente experiencias que adquieren un significado humano diferente tanto para el estudiante como para el maestro.

Cada filósofo o cada problema o cada acontecimiento está inmerso en un contexto tal que cuando uno quiere comprender, la idea de la justicia o la expansión de los espacios metropolitanos o el pensamiento liberal mexicano, uno se ve obligado a entrar en diálogo (tanto con el autor como con los textos, tanto con la realidad como con lo que dicen los expertos en ella, tanto con el momento histórico en el que se dice y en el que se lee así como con la experiencia misma) y uno no comprende hasta que no se da esa fusión de horizontes.

La labor entonces es hacer que ese intercambio se reviva y se entienda. Pero también es cierto que comprender (al autor o comprender el contexto histórico, comprender el problema real y comprender lo que nos dicen los expertos acerca de él, comprender un momento histórico y la interpretación que de ese momento se ha hecho) no se reduce sólo a este ámbito de diálogo. Tanto la obra de un filósofo como los problemas de una civilización, y por supuesto los acontecimientos históricos de México, se realizan en un horizonte más amplio como puede ser el 
FERNANDO CALOCA

diálogo con la historia y la tradición. Y gracias al diálogo es que puede haber apertura y ampliación de horizontes.

Los textos que leemos son en este sentido respuestas particulares a preguntas fundamentales que se van presentando a la inteligencia humana. La reflexión que se genera en una clase de Ideas o de Problemas o de Historia, * constituye un proceso de conservación y de innovación. Desde nuevos horizontes se amplían y replantean los objetos del pensamiento.

Cualquier universitario que quiera comprender la realidad a través de un autor determinado descubre inmediatamente un proceso dialogal de la tradición en el que ese autor está inmerso, e incluso quiénes son sus interlocutores. La pretensión de originalidad que vemos en muchos autores no hace sino encubrir tramposamente o con soberbia cuáles son las pistas de su propio diálogo.

Los maestros, en cambio, como lo sugieren las ideas de Gadamer, deben presentar a los interlocutores del diálogo que se representa en un autor o durante una clase, una manifiesta vocación de no aparecer personalmente como subjetividad sino como testigo del acontecer de la idea, el problema o el acontecimiento en el desvelamiento de su verdad. ${ }^{61}$

44 Las clases de Estudios Generales guardan este estrecho vínculo con la hermenéutica filosófica.

El hecho de que la interpretación de un texto no tenga como objetivo comprender al autor sino la verdad del texto tiene especial relevancia

* El autor se refiere a los cursos de Ideas e instituciones políticas y sociales; Problemas de la civilización contemporánea; e Historia socio-política de México, materias que pertenecen al programa académico de nuestro Departamento. (n.r.)

${ }^{61}$ En este sentido, el ejemplo lo hallamos en VMI, en que Gadamer dialoga con los problemas y va tomando nota o va levantando el acta de lo que la historia de la filosofía le va enseñando. El propio pensamiento de Gadamer no está expresado en primera persona sino a través de las interpretaciones de los autores con los que dialoga. Y lo que es propio de la hermenéutica filosófica, el objetivo de ese diálogo no es comprender al autor, como sostiene la hermenéutica clásica, sino la verdad de lo que dice. 
para los cursos de Estudios Generales. Ya no tiene sentido el estudio de la historia de la filosofía como una galería de autores e ideas sin ninguna relación con los problemas actuales sin más afán que el puramente coleccionador. El estudio que se propone en estos cursos y que satisface verdaderamente a los objetivos de cada uno de ellos, en mi opinión, tiene que ver con ser capaz de comprender la realidad. Para comprender debemos dejarnos decir algo y contemplar la verdad que revelan las ideas de ese autor desde su propio contexto vital e histórico así como la verdad que a nosotros nos sigue diciendo algo desde nuestro propio horizonte. Aprendemos a pensar con las ideas filosóficas. Gadamer tiene la convicción de que los textos ‘clásicos’ son interlocutores nuestros que nos hablan como un tú. Los clásicos son los interlocutores permanentes que siempre tienen algo que decirnos ante las nuevas preguntas que les hacemos desde nuestro propio horizonte. No se trata pues de torturar a nadie con la idea de que debe estudiar de memoria aquello que lee sino que también es muy importante que reflexione acerca de lo leído para que pueda emitir una valoración que le permita apropiarse de las ideas o problemas que se le están planteando de parte de la realidad.

Interpretar un texto no tiene que ver con el intento de reproducir lo ya dicho por el autor sino que se trata mas bien de un acto productivo en el que ante nuevas preguntas surgen nuevas respuestas. Esta actualización permanente a la que los textos clásicos en particular nos invitan es llamado por Gadamer principio de historia efectual:

el que intenta comprender está ligado a la cosa transmitida y mantiene o adquiere un nexo con la tradición de la cual habla el texto transmitido. ${ }^{62}$

La invitación es a caer en la cuenta de que los textos de los autores clásicos siguen hablándonos y revelándonos su verdad mas allá de lo expresamente querido o previsto por ellos mismos. En este sentido

${ }^{62}$ VMII, p. 68. 
FERNANDO CALOCA

se entiende que sea inútil o absurdo pretender comprender objetivamente a un autor. Sólo comprendemos, dice Gadamer, en la medida en que anticipamos un proyecto o prejuicio desde nuestro horizonte actual conforme al cual formulamos nuestras preguntas y lo valoramos. Por supuesto que esto significa una crítica a la objetividad en sí misma para conseguir la interpretación definitiva sobre cualquier texto, autor, problema o acontecimiento; pero es más una invitación a no ser dogmáticos sobre todo si tomamos en cuenta que el horizonte en el que vivimos siempre es abierto y móvil.

Si la historia está viva y se rescribe siempre, la razón de esto no es nada más porque conozcamos más datos de los acontecimientos sino porque comprendemos de manera diferente: el horizonte en el que hacemos las preguntas sobre la verdad de aquello ha cambiado, y esto permite que haya nuevas preguntas y nuevas respuestas.

A las personas que tienen la vocación del maestro, mejor que a nadie, les viene bien eso de renovarse o morir como forma de vida. Pero la renovación no viene únicamente de que se está permanentemente en cursos de actualización o de que se está constantemente leyendo la última interpretación de la mesa de novedades en alguna librería, sino 46 que las clases, el diálogo con los estudiantes y el afán de estar haciendo preguntas a los textos son una experiencia que por sí misma constituye dicha renovación.

Precisamente el horizonte cambiante y móvil es el que nos permite obtener nuevos datos e interpretaciones correctas o incorrectas de los textos. En la hermenéutica filosófica de Gadamer no es posible postular una interpretación objetiva, definitiva o metódica sino que en la medida en que nos sometemos a los textos (o al diálogo con los alumnos en clase) con una actitud abierta hacia ellos mismos, nos dejamos decir algo por ellos y dejamos que aparezca la verdad, comprendemos algo nuevo.

Dar una clase está muy lejos de proporcionar una certeza como la que es capaz de proporcionar un método experimental. Decimos que para aprender a pensar no hay recetas. El método científico tradicional para Gadamer tiene más que ver con el proceso de exposición o demostración de una verdad que con el descubrimiento de la misma 
en el proceso dialógico del pensar. El diálogo como intercambio de pregunta y respuesta supone siempre una crítica a cualquier forma de dominación incluyendo la de la metodología científica y técnica actuales. Los prejuicios aquí son inevitables pero Gadamer es un autor que confiere a los prejuicios un carácter positivo y no negativo como lo hace la metodología científica tradicional. Siempre comprenderemos desde nuestros propios prejuicios. Pero si estamos abiertos a un texto, a un diálogo con el alumno, a un problema de la civilización contemporánea, debemos respetar la alteridad; es decir el valor del otro o lo otro para que ese prejuicio pueda ser confirmado, en cuyo caso nos habrá servido de orientación en la tarea de comprender, o bien el prejuicio será destruido porque provendrá de una incorrecta apreciación de parte nuestra. La verdad no se deja ver cuando la forzamos a que sea vista, en cambio sale a flote sólo cuando en la relación, en el intercambio, en el diálogo, dejamos que salga cuando quiera:

debemos aprender que escuchando al otro se abre el verdadero camino en el que se forma la solidaridad. ${ }^{63}$

Ya al final de su vida, el propio Gadamer trató de justificar por qué sólo se puede aprender a través de la conversación. Sostuvo que la educación es educarse, que la formación es formarse. ${ }^{64}$ Desde que

63 "La diversidad de las lenguas y la comprensión del mundo" (1990) en Arte y verdad de la palabra (1993), 1997, Barcelona, Paidós, p. 125, prol. Gerard Vilar, trad. F. Oncina y J. F. Zúñiga.

${ }^{64}$ La educación es educarse (1999), 2000, Barcelona Paidós, trad. Francesc Pereña Blasi (en adelante $E E$ ). Se hizo una trascripción exacta de una grabación magnetofónica. En el curso de la conferencia Gadamer, además, hace un balance de sus propios empeños educativos, hablando de experiencias personales e ilustrando con ejemplos los efectos que pueden tener en la configuración de una personalidad determinados influjos y acontecimientos externos. Se exponen ideas sobre el proceso educativo en la familia, la escuela y la universidad. Algunas consideraciones como el papel preponderante de la capacidad de hablar y del aprendizaje de la lengua, las modestas 
FERNANDO CALOCA

vamos desarrollando la capacidad de hablar y aprendemos la lengua materna nos percatamos de que nos educamos a nosotros mismos: uno se educa. Ya en la escuela y en la universidad caemos en la cuenta de lo difícil que es, pero al mismo tiempo lo necesario de la comunicación para lograr una auténtica formación humana.

Todo proceso de formación humana de lo que trata es de que el hombre acceda él mismo a su morada. La morada de los hombres es, para Gadamer, el lenguaje.

Que alguien que crece en condiciones modestas se muestre bien educado es algo que se nota en la manera de hablar, algo que le da un atractivo que percibimos enseguida con respeto. ${ }^{65}$

La educación es un proceso natural que cada cual acepta siempre cordialmente procurando entenderse con los demás. ${ }^{66}$ Existe como una especie de receptor que permite a uno captar aquello que necesita saber pero que sólo puede captar en el trato con los demás. De hecho eso mismo es lo que uno necesita más o menos para poder entenderse con el otro. En suma, el diálogo sirve para comprender la realidad y comprendernos a nosotros mismos en ella.

posibilidades de los maestros, las oportunidades y peligros de la era informática, la importancia de los programas de estudio, los métodos de enseñanza y las asignaturas, con especial atención a las matemáticas, los problemas del funcionamiento masivo de la universidad, la ética del rendimiento, el optimismo del progreso y las especializaciones en relación con el llegar a estar en casa en nuestro mundo.

${ }^{65}$ EE, p. 24-5.

${ }^{66}$ Gadamer gusta mucho de referir la definición de Hegel en la Fenomenología del espíritu acerca de la formación: poder contemplar las cosas desde la posición de otro. 